\title{
Postural orientation, what to expect in youth athletes? A cohort study on data from the Malmö Youth Sport Study
}

\author{
Sofia Ryman Augustsson ${ }^{1,2^{*}}$, Jenny Nae ${ }^{2}$, Magnus Karlsson ${ }^{3}$, Tomas Peterson ${ }^{4}$, Per Wollmer ${ }^{5,6}$ and Eva Ageberg ${ }^{2}$
}

\begin{abstract}
Background: Studies investigating postural orientation in uninjured youth athletes are scarce. Understanding how postural orientation during functional performance tests change with age in uninjured athletes has the potential to enhance awareness of changes in performance after injury and to set realistic goals for injured athletes. Thus, the aim of this study was to explore postural orientation during functional tasks at early adolescence, and changes in postural orientation from early to middle adolescence and relate this to sex, type of sport and right leg lean body mass (RLLBM).

Methods: In this cohort study 144 (38\% female) youth athletes (mean age 13.5 years, SD 0.3) were included at baseline and 86 of these at follow up 2 years later. Four functional performance tests were visually evaluated for Postural Orientation Errors (POEs) with an ordinal scale, ranging from 0 (good) to 2 (poor), yielding a maximum total POE score of 51, and RLLBM by dual energy X-ray absorptiometry.

Results: Improvements were observed in the total POE score from baseline to follow-up, median difference - 10 and $-7(p<0.001)$ for female and male athletes, respectively. At follow-up, female athletes had lower total POE score (median 18) than males (median 24) $(p=0.01)$. There were no differences in POE scores between sports type (team, individual, aesthetic) ( $p=0.20-0.98)$ and no relationship between total POE score and RLLBM $\left(r_{s}=0.09, p=\right.$ 0.42).
\end{abstract}

Conclusions: POEs appear to be quite common in young athletic population, but improvements are achieved over time. At mid-adolescence, female athletes seem to have less POEs than males. Neither sport type nor RLLBM seem to influence postural orientation.

Keywords: Postural orientation errors, Functional performance, Sex difference, Lean body mass

\section{Background}

Functional performance tests for assessment of sport performance often include tests of muscle strength, endurance and/or power [1-3] and in some cases movement quality $[4,5]$. However, most of the studies $[4,5]$ on movement quality are performed on young adults

\footnotetext{
* Correspondence: sofia.rymanaugustsson@lnu.se

${ }^{1}$ Department of Sport Science, Faculty of Social Sciences, Linnaeus University, SE-391 82 Kalmar, Sweden

${ }^{2}$ Department of Health Sciences, Lund University, Lund, Sweden

Full list of author information is available at the end of the article
}

and studies on movement quality in youth athletes are scarce [6]. Functional and sport performance gradually improve with maturation [7] and full development of a specific skill depends on full maturation of the nervous system [8]. During maturation there are progressive changes in muscle mass, power and strength, which are of importance for the improvement of physical performance [9]. However, these developments vary between sexes with general greater improvements for boys [9-11] that continues to advance during adolescence compared

C C The Author(s). 2021 Open Access This article is licensed under a Creative Commons Attribution 4.0 International License, which permits use, sharing, adaptation, distribution and reproduction in any medium or format, as long as you give appropriate credit to the original author(s) and the source, provide a link to the Creative Commons licence, and indicate if changes were made. The images or other third party material in this article are included in the article's Creative Commons licence, unless indicated otherwise in a credit line to the material. If material is not included in the article's Creative Commons licence and your intended use is not permitted by statutory regulation or exceeds the permitted use, you will need to obtain permission directly from the copyright holder. To view a copy of this licence, visit http://creativecommons.org/licenses/by/4.0/ The Creative Commons Public Domain Dedication waiver (http://creativecommons.org/publicdomain/zero/1.0/) applies to the data made available in this article, unless otherwise stated in a credit line to the data. 
to girls who reach an earlier plateau [9]. Hence, an important factor to consider when examining youth athletes is their sex and age because this may influence their functional performance, including quality of movement.

Postural orientation is one aspect of movement quality, which is defined as the ability to maintain an appropriate relationship between the body segments and between the body and the environment when performing a task [12]. Postural orientation is one component that, together with postural stability, constitutes postural control [13]. Postural control has been noted to be important for performance in several sports [14-16]. For example, soccer players have been found to have better postural control, in terms of less postural sway, compared to participants involved in limited contact sport or no sport at all [14]. However, to our knowledge, research on the relationship between postural orientation and sport performance seem to be lacking.

For postural orientation of the lower extremity, the knee joint is often described as normal (aligned), varus, or valgus [17] where valgus has been highlighted as a factor associated with knee injury [18-20]. For example, some anterior cruciate ligament (ACL) tears in sports involve a noncontact mechanism, with the lower extremity displaying a dynamic knee valgus moment at the impact of injury [18]. Furthermore, patients with ACL injury seem to have different lower limb biomechanics [21], in addition to poorer trunk control [22] and poorer postural stability [13], compared with healthy controls. However, the interpretation of data from these studies in a clinical setting without any reference values from an uninjured population is challenging.

From a sport medical perspective, reference values from age-matched athletic controls without injury are important to identify any abnormal and/or impaired values when testing groups of patients. To our knowledge, there is only one study [23] investigating postural orientation during a functional performance task in healthy children and adolescence (from 9 to 16 years of age). In that study, no differences between sexes in absolute values were noted but a different effect of age for boys and girls [23]. However, only one dynamic test, the single-limb mini squat, was performed to assess postural orientation and only the medio-lateral knee position was analyzed [23]. In addition, no data on sport participation were specified for the participants in the study, thus, it was unclear whether they were athletes. Thus, studies investigating postural orientation in youth athletes without injury are warranted.

Understanding how postural orientation during functional performance tests change with age in uninjured athletes has the potential to enhance awareness of changes in performance after injury and to set realistic goals for injured athletes. The knowledge from the present study could help sport physical therapists, coaches and/or athletic trainers when assessing functional performance in young athletes.

The aims of this study were to explore: 1) postural orientation during functional tasks at early adolescence (baseline assessment); 2) any changes in postural orientation from early to middle adolescence (baseline to follow-up 2 years later); 3) any sex differences in postural orientation; 4) differences in postural orientation between different sports; and 5) the relation between postural orientation and lean body mass, in youth athletes.

\section{Methods}

\section{Study design}

Data for this cohort study, following to the STROBE statement [24], were collected during 2013-2017 as part of the Malmö Youth Sport Study (MYSS), in detail described in previous publications $[25,26]$. In summary, MYSS is an ongoing longitudinal cohort study, including boys and girls (later young men and women), investigating physiological, psychological and social factors associated with sports performance, academic success and long-term physical activity [25]. The participants in the MYSS project are young athletes attending a sport school in the southern part of Sweden, a part of the Swedish National Sport Education program, aiming for an elite career. The selection criteria for acceptance to the school are sport merits and one of the aims of the education is sport talent development. The school provides organized sport specific training during school hours allowing students to combine educational work with sports. The students practice their sport during school hours ( $\geq 450 \mathrm{~min} /$ week) outside regular training and competitions after school.

\section{Participants and procedure}

In this report, we included athletes who were involved in team sports (soccer, ice hockey, floorball and basketball), individual sports (swimming, athletics, tennis, badminton and squash), or aesthetic sports (diving, figure skating and artistic gymnastics). From the total cohort of the MYSS project $(n=156), 144$ ( $38 \%$ girls) healthy adolescent athletes were included. Thirteen-year old athletes were assessed at baseline, during the winter months (2013-2014 and 2014-2015), (Fig. 1, Table 1) and, of these, 86 were assessed approximately 2 years later at the same season and with the same test battery. Their mean (SD) age was $13.5(0.3)$ years at baseline and 15.6 (0.3) years at follow up.

Trained physiotherapists collected data, with videorecording, for functional performance tests at the athletes' school. Anthropometrics (height, weight and total body lean body mass (TBLBM) were measured in a 


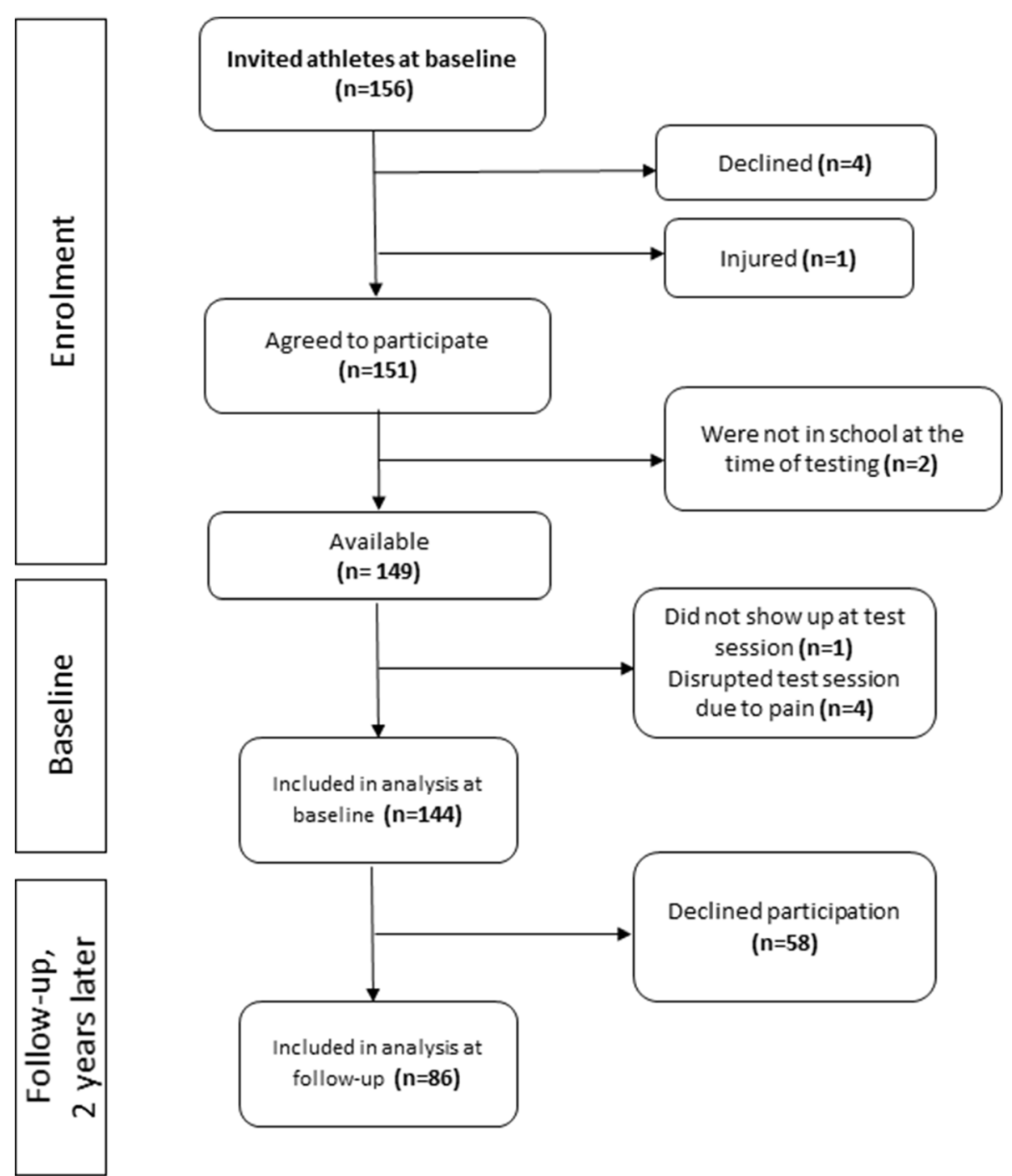

Fig. 1 Flow chart of inclusion process of athletes for the evaluation of postural orientation errors (POEs)

laboratory setting at another occasion within 1-3 months from the functional performance test session. Athletes with any difficulty moving around on the day of testing, or reports of lower extremity injury, limiting the completion of the tasks, were excluded $(n=1)$.

\section{Measurements of postural orientation errors}

The athlete's performance during 4 functional performance tests, previously described by Nae et al. [27, 28], was videotaped, using a digital camcorder $(1920 \times 1080$ pixels; $30 \mathrm{~Hz}$; Everio GZ-HM650BE; JVC, Yokohama, Japan) placed on a tripod in front of the athlete, perpendicular to the frontal plane, for later assessment of Postural Orientation Errors (POEs). To ensure that the whole movement was captured during testing, the camera was positioned $2-4 \mathrm{~m}(\mathrm{~m})$ in front of the athlete in line with his or her waistline (approx. $1 \mathrm{~m}$ off the floor).
Athletes were instructed to wear shorts and a tight top. The first test (single-leg mini squat) was performed barefoot, whereas in the remaining tests athletic shoes were worn. All athletes performed the tests in the order that they are described below, starting on the right leg. Prior to each test, the test leader gave standardized instructions along with a visual demonstration of the test. The athlete was allowed 2-3 practice trials per test, or per side for the one-legged test, before initiating the testing. For the Drop-jump, practice trials were given until the athlete was familiarized with the procedure.

\section{Single-leg mini squat}

For the Single-leg mini squat (SLS), the athlete was standing with the arms alongside the body on one leg and with the second toe placed on a longitudinal line. The athlete was asked to bend his/her knee, without 
Table 1 Athletes' characteristics for female and male athletes at baseline $(n=144)$ and at follow-up $(n=86)$

\begin{tabular}{|c|c|c|c|c|}
\hline Anthropometrics & $\begin{array}{l}\text { Male athletes at baseline } \\
(n=90)\end{array}$ & $\begin{array}{l}\text { Male athletes at follow-up } \\
(n=52)\end{array}$ & $\begin{array}{l}\text { Female athletes at baseline } \\
(n=54)\end{array}$ & $\begin{array}{l}\text { Female athletes at follow- } \\
\text { up }(n=34)\end{array}$ \\
\hline & Mean (SD) & Mean (SD) & Mean (SD) & Mean (SD) \\
\hline Height (cm) & $163(10)$ & $176(8)$ & $161(6)$ & $166(6)$ \\
\hline Weight (kg) & $51(10)$ & $65(10)$ & $52(6)$ & $60(6)$ \\
\hline $\begin{array}{l}\text { TBLBM (\% of } \\
\text { bodyweight) }\end{array}$ & $78(0.6)$ & $80(0.4)$ & $71(0.4)$ & $68(0.4)$ \\
\hline Main Sport & $\mathrm{n}$ & $\mathbf{n}$ & $\mathbf{n}$ & $\mathbf{n}$ \\
\hline Football ${ }^{a}$ & 41 & 26 & 17 & 9 \\
\hline Ice hockey ${ }^{a}$ & 11 & 8 & 5 & 4 \\
\hline Basketball ${ }^{a}$ & 9 & 2 & 6 & 4 \\
\hline Floorball $^{a}$ & 5 & 3 & 6 & 4 \\
\hline Swimming ${ }^{b}$ & 7 & 3 & 3 & 2 \\
\hline Athletics ${ }^{b}$ & 0 & 0 & 7 & 4 \\
\hline Tennis $^{b}$ & 7 & 5 & 2 & 1 \\
\hline Squash ${ }^{b}$ & 1 & 1 & 0 & 0 \\
\hline Badminton $^{\text {b }}$ & 4 & 1 & 0 & 0 \\
\hline Diving $^{c}$ & 1 & 0 & 4 & 3 \\
\hline Figure skating ${ }^{c}$ & 1 & 1 & 4 & 3 \\
\hline$\underset{c}{\text { Artistic gymnastics }}$ & 3 & 2 & 0 & 0 \\
\hline Type of sports & $\mathrm{n}$ & $\mathbf{n}$ & $\mathbf{n}$ & $\mathbf{n}$ \\
\hline Team $^{a}$ & 66 & 39 & 34 & 21 \\
\hline Individual ${ }^{\mathrm{b}}$ & 20 & 10 & 16 & 10 \\
\hline Aesthetic ${ }^{c}$ & 4 & 3 & 4 & 3 \\
\hline
\end{tabular}

TBLBM Total body lean body mass

${ }^{\text {a }}$ Team sports

bIndividual sports

'Aesthetic sports

bending forward from the hip, until he/she no longer could see the line along the toes (corresponding to about 50 degrees of knee flexion), and then return to extension. The test was repeated 5 times on each leg and POEs were assessed during the entire movement, from starting position through return to this same position.

\section{Forward lunge}

For the Forward Lunge (FL), the athlete was standing with the arms alongside the body and with feet hipwidth apart on the floor. The athlete took a long stride forward, about $1 \mathrm{~m}$, flexed the knee to approximately $90^{\circ}$, and pushed back to starting position by extending the front leg. The test was repeated 5 times on each leg and the front leg was assessed in the landing phase from initial contact until maximum flexion of the knee.

\section{Drop-jump}

The Drop-jump (DJ) test was performed with the athlete standing on a step board, approximately $30 \mathrm{~cm}$ high, with feet hip-width apart. The athlete dropped from the step-board with both feet leaving the box simultaneously, then performed a maximal vertical jump upon landing. Arm swing was allowed during the jump and the jump was repeated 3 times. The POEs were assessed during the first landing, from first contact with the floor to extended knees.

\section{Single-leg hop for distance}

For the Single-leg hop for distance (SLHD), the athlete was standing on one leg, with the other leg lifted from the floor by flexing the knee. The athlete jumped forward as far as possible, taking off and landing on same foot with a safe and controlled landing maintaining balance on landing for 2 to $3 \mathrm{~s}$. Arm swing was allowed during the jump. The test was repeated 3 times and POEs were assessed during landing, from first contact with the floor to extended knee.

\section{Scoring of postural orientation errors}

A trained physical therapist (SRA) observed and rated POEs from the video recordings according to a 
previously evaluated protocol [28]. POEs were assessed by evaluating 1) pronation of the foot (SLS only), 2) knee medial-to-foot position (KMFP), 3) femoral valgus, 4) deviation of pelvis in any plane (lateral deviation, tilt and/or rotation of pelvis) and 5) deviation of trunk in any plane (forward, lateral and/or rotation) as described [28].

A 3-point ordinal scale, ranging from 0 to 2, was used for the evaluations, with 0 indicating good postural orientation (no signs of POEs), 1 fair (minimal signs of POEs), and 2 poor (clear signs of POEs). When the execution of the test did not have any similarities to the test a score of 3 was given, representing very poor postural orientation, thus the maximum within-task POE score was given [28]. A POE was scored as fair or poor when it occurred at least 3 out of 5 times in the tasks performed with 5 repetitions and at least 2 out of 3 times in the tasks performed with 3 repetitions (Table 2). Both the within-tasks POE score (the sum of all POEs within a task), and the total POE score were calculated to a percentage scale (0-100) and used in the analyses (Table 2).

\section{Reliability analysis}

Intra-rater and inter-rater reliability were evaluated from 10 athletes' video recordings for within-task POE score and total POE score. Inter-rater reliability was assessed by two authors (SRA and JN) for each within-task POE score with Cohen's kappa [29, 30] and showed moderate to almost perfect agreement (kappa values from 0.74 to $0.88, p \leq 0.0001$ ), according to Landis and Koch [31]. Intra-rater reliability, analyzed on two separate occasions within 2 weeks, for each within-task POE (assessed by the author SRA) was calculated with intra-class correlation coefficient $\left(\mathrm{ICC}_{2,1}\right)$, with the two-way random effect model (absolute agreement definition, 95\% confidence intervals (CI)) and indicated excellent agreement $\left(\mathrm{ICC}_{2,1}\right.$ value from 0.824 to $\left.0.98, p \leq 0.002\right)$. Interrater reliability for total $\mathrm{POE}$ score showed excellent agreement (Cohen's kappa value 0.875, $p<0.001$ ). A Wilcoxon's rank test was also calculated, revealing no systematic difference between raters for the total POE score $(p=0.32)$. Total POE score for intra-rater reliability, assessed with $\mathrm{ICC}_{2,1}$, was 0.95 (CI: 0.82-0.99, $p<0.001)$.

\section{Anthropometry}

Body height $(\mathrm{cm})$ was measured, with a Holtain Stadiometer (Holtain LTD, Pembrokeshire, UK) and body mass $(\mathrm{kg})$ with an electric scale (Avery Berkel HL 120 Electric Scale, Avery Berkel, West Midlands, UK). Total body lean body mass (TBLBM) and right leg lean body mass (RLLBM) was measured by dual energy X-ray absorptiometry (DXA) (iDXA ${ }^{\circ}$ version enCore 13.60, Lunar Corporation, Madison, WI, USA). When estimating TBLBM and RLLBM we used a total body scan and standard adult software. The measurements were done with the participants non fasting, dressed in light clothes, with no shoes, and with the athletes in a supine position according to standard procedure recommended by the manufacturer. Two trained research technicians performed all measurements and software analyses. All measurements were done within 1-3 months from the functional performance test session. The DXA apparatus was calibrated daily, by use of a phantom. Coefficient of variation $(\mathrm{CV} \%)$ was for TBLBM $0.6 \%$.

\section{Statistical methods}

Statistics were calculated using IBM SPSS (IBM SPSS Statistics for Windows, Version 23.0. IBM, Armonk, NY). Descriptive data are presented with median and quartiles for categorical data, while means and standard deviation (SD) were used to describe continuous data. A small, likely non-clinically relevant, difference was found between the right (median 3, quartiles 1-4) and left legs (median 2, quartiles $2-3)$ in the DJ test $(p=0.002)$. No other differences were observed between the right and left legs; therefore, data were analyzed for the right leg only. For drop-out analysis, demographic data (height and weight) and baseline screening results are presented for the drop-outs (those who did not attend at followup, $n=58$ ) and the participants (included in the followup analysis, $n=86$ ). Males and females were analyzed separately except for the comparison between sports type (team, individual, aesthetic sports). For comparison baseline vs follows up, data were analyzed with the Wilcoxon's rank test for POEs and with the Pairedsample t-test, with $95 \% \mathrm{CI}$, for RLLBM. TBLBM value is expressed in $\mathrm{kg}$ and percentage of body weight together with relative to bodyweight (rTBLBM). The Mann-

Table 2 Tasks, POEs within each task, and calculations for the percentage scale (within-task and total POE scores)

\begin{tabular}{lllllll}
\hline Functional Task & Foot Pronation & KMFP & Femoral valgus & Pelvis segment & Trunk Segment & Within-Task POE Score \\
\hline Single-leg mini-squat & $X$ & $X$ & $X$ & $X$ & $X$ & $\frac{\text { sum score }}{15} \times 100$ \\
Forward lunge & & $X$ & $X$ & $X$ & $X$ & $\frac{\text { sum score }}{12} \times 100$ \\
Drop Jump & & $X$ & $X$ & $X$ & $\frac{\text { sum score }}{12} \times 100$ \\
Single-leg hop for distance & & $X$ & $X$ & & $X$ & $\frac{\text { sum score }}{12} \times 100$ \\
Total POE score & & & & $\frac{\text { sum score }}{51} \times 100$
\end{tabular}

KMFP knee medial to the foot position 
Whitney U test was used for comparison between sexes, and the Kruskal-Wallis $\mathrm{H}$ for comparison between sports type. Differences between POE score for different tests were analyzed with Friedman Test and Wilcoxon's rank test. Fisher's exact test was used to assess any differences in the distribution of males and females between the groups of different sports type. The Spearman's correlation coefficient was used to analyze the association between changes in POEs (median difference baseline vs follow-up) and changes in RLLBM (mean difference baseline vs follow-up). The level of significance was set at $p \leq 0.05$.

\section{Results}

\section{Participants - drop-out analysis}

A total of 144 athletes were screened at baseline and, of these, 86 athletes were included in the follow-up analysis. At baseline, the total POE score was 29 ( $q 1-3=12$ ) for the drop-outs $(n=58)$ and $31(\mathrm{q} 1-3=13.5)$ for the follow-up participants $(n=86)$. Table 3 gives the baseline values for total POE score, weight, and height at baseline for female drop-outs $(n=20)$ and follow-up participants $(n=34)$ and male drop-outs $(n=38)$ and follow-up participants $(n=52)$.

\section{Baseline assessments of postural orientation errors}

Within-task POE scores for each task and total POE score, at baseline, are given in Table 4 for female and male athletes as well as POE scores according to sports type. Median POE score in SLS and SLHD were significantly higher compared to FL and DJ for both females and males $(p<0.001)$.

\section{Changes in postural orientation errors over time}

There were significant improvements in the total POE score between baseline and follow-up for both female $(p<0.0001)$ and male athletes $(p<0.0001)$ (Table 5). There were also improvements in all tests (SLS, $p=$ 0.001; FL, $p<0.001$; DJ, $p<0.001$; SLHD, $p=0.024$ ) for females and in FL $(p<0.001)$, DJ $(p<0.001)$ and SLHD $(p=0.001)$ for males.

\section{Sex differences}

At baseline, no differences were found between males and females for any POE scores $(p=0.06-0.42)$. At follow-up, female athletes scored better in the SLS test $(p=0.004)$ and had lower total POE score than males $(p=0.01)$ (Table 5).

\section{Postural orientation errors in different sports type}

POE scores according to sports type are presented in Table 6. There were no differences in sex distribution between the groups of different sports type $(p=0.40)$. No differences in POE scores were found between sports type (team, individual, aesthetic) at baseline $(p=0.20$ 0.98 ) whereas aesthetic athletes performed significantly better in SLS at follow-up compared to team athletes $(p=0.02)$. All groups significantly improved Total POE score $(p=0.0001-0.04)$.

\section{Lean body mass and the association between POEs and RLLBM}

There was a significant increase of $12 \mathrm{~kg}$ (95\% CI 11 to $13, p<0.001)$ in TBLBM for the male athletes $(n=52)$, from baseline to follow-up, corresponding to an rTBLBM of $2 \%$ (95\% CI 1 to 3) increase. RLLBM increased with $2 \mathrm{~kg}$, from 6.8 to $8.9 \mathrm{~kg}$, (95\% CI 1.8 to 2.3 , $p<0.001)$. For the female athletes $(n=34)$, the TBLBM had increased by $4 \mathrm{~kg}(95 \% \mathrm{CI} 3$ to $5, p<0.001)$ but decreased in rTBLBM by $3 \%(95 \% \mathrm{CI}=2$ to $4, p<0.001)$ from baseline to follow-up. RLLBM increased with 0.8 $\mathrm{kg}$, from 6.3 to $7.1 \mathrm{~kg}$, (95\% CI 0.5 to $0.9, p<0.001)$. No relationship was found between the total POE score difference (baseline vs follow-up) and RLLBM difference (baseline vs follow-up) for male $\left(\mathrm{r}_{\mathrm{s}}=0.15, p=0.31\right)$ or female athletes $\left(r_{s}=0.436, p=0.482\right)$, or for the total cohort $\left(\mathrm{r}_{\mathrm{s}}=0.09, p=0.42\right)$ (Fig. 2).

\section{Discussion}

The main observation in this study was that POEs seem to be quite common in early adolescent athletes. Both female and male athletes demonstrated rather high POE scores, indicating poor postural orientation, at age 13 with no differences between females and males $(p \geq$ $0.06)$. Thus, appropriate postural orientation may not be expected in this young population. When examined 2 years later, both female and male athletes improved their total POE score between baseline and follow-up but female athletes scored significantly better in the total POE score $(p=0.012)$. Neither sport type nor LBM was associated with POE scores.

Table 3 Total POE score, presented with median together with q1-3, height ( $\mathrm{cm}$ ) and weight (kg) presented with mean (SD) for drop-outs and follow-up participants (FUP)

\begin{tabular}{lllll}
\hline & Female drop-outs $(\boldsymbol{n}=\mathbf{2 0})$ & Female FUP $(\boldsymbol{n}=\mathbf{3 4})$ & Male drop-outs $(\boldsymbol{n}=\mathbf{3 8})$ & Male FUP $(\boldsymbol{n}=\mathbf{5 2})$ \\
\hline Total POE score & $26(8.5)$ & $31(15.5)$ & $31(12)$ & $31(12)$ \\
Height $(\mathbf{c m})$ & $162(7)$ & $162(6)$ & $164(10)$ & $164(9)$ \\
Weight $\mathbf{( k g})$ & $52(6)$ & $52(6)$ & $52(11)$ & $50(9)$ \\
\hline
\end{tabular}


Table 4 Within-task POE score for the single-leg mini squat (SLS), forward lunge (FL), drop jump (DJ) and single leg hop for distance (SLHD), and total POE score, are presented for right leg, female and male athletes and for different sports type (team, individual, aesthetic) at baseline ( $n=144)$. Values are median (quartiles, minimum-maximum)

\begin{tabular}{llllll}
\hline Task/POE & $\begin{array}{l}\text { Females } \\
(\boldsymbol{n}=\mathbf{5 4 )}\end{array}$ & $\begin{array}{l}\text { Males } \\
(\boldsymbol{n}=\mathbf{9 0})\end{array}$ & $\begin{array}{l}\text { Team } \\
(\boldsymbol{n}=\mathbf{1 0 0} ; \text { female } \boldsymbol{n = 3 4 )}\end{array}$ & $\begin{array}{l}\text { Individual } \\
(\boldsymbol{n}=\mathbf{3 6} \text { f female } \boldsymbol{n = 1 6 )}\end{array}$ & $\begin{array}{l}\text { Aesthetic } \\
(\boldsymbol{n}=\mathbf{8} ; \text { female } \boldsymbol{n = 4 )}\end{array}$ \\
\hline SLS & $33(20 ; 40,13 ; 60)$ & $33(20 ; 47,13 ; 73)$ & $33(20 ; 47,13 ; 73)$ & $33(20 ; 45.25,13 ; 60)$ & $33(21.75 ; 42.25,13 ; 53)$ \\
FL & $25(17 ; 42,0 ; 58)$ & $25(17 ; 33,0 ; 58)$ & $25(17 ; 39.75,0 ; 58)$ & $25(17 ; 33,0 ; 58)$ & $12,5(8 ; 39.75,0 ; 50)$ \\
DJ & $25(17 ; 22,0 ; 58)$ & $25(8 ; 33,0 ; 67)$ & $25(10.25 ; 33,0 ; 67)$ & $17(8 ; 31,0 ; 42)$ & $25(2 ; 31,0 ; 50)$ \\
SLHD & $33(25 ; 44,8 ; 75)$ & $33(25 ; 58,17 ; 83)$ & $33(25 ; 50,17 ; 83)$ & $33(25 ; 56,17 ; 75)$ & $29(21 ; 51.75,8 ; 58)$ \\
Total POE score & $28(24 ; 35.5,10 ; 53)$ & $31(25 ; 37,12 ; 55)$ & $31(25 ; 37,14 ; 55)$ & $26(24 ; 32.5,10 ; 53)$ & $27(21.25 ; 33.5,12 ; 53)$ \\
\hline
\end{tabular}

The total POE score (28 and 31 for females and males, respectively) at the age of 13 , noted in the present study, are higher than POE scores noted in women (26) and men (20.5) with ACL injury (mean (SD) age 26.7 (6.5) [32]. However, in the study on ACL injured participants, the test battery consisted of five test of functional task and six segment-specific POEs yielding a higher maximum total POE score of 73. The median POE score for $F L$ and $D J$ test was 25 respectively and 33 for both the $S L S$ and SLHD test. This indicates that, at early adolescence, we can expect POEs to a fairly large extent in functional tasks, which is important knowledge for professions that examine athletes in different aspects of neuromuscular control. The POE scores for the SLS and the $S L H D$ was higher than for the $F L$ and $D J$, indicating that the SLS and SLHD may better detect POEs in this young athletic population compared to $F L$ and $D J$. Further, the higher scores for the SLS and the SLHD suggests that unilateral tests are, not surprisingly, more demanding for maintaining appropriate postural orientation than two-legged tests. One advantage of single-leg tests is their ability to detect between-limb imbalances [33] and thus, might be more useful when aiming to detect postural orientation errors between injured and non-injured limb.

The significant improvements in the total POE score between baseline and follow-up could be related to natural neuromuscular improvements from early to mid- adolescence. In a previous study on youth tennis players, the authors found large age effects on neuromuscular lower-limb asymmetries (between-limb differences) [33]. However, contrary results have been found in other investigations [10, 34]. In a study on elite male youth soccer players, the stage of maturation did not show any effect on the level of asymmetry, in functional performance tasks, in terms of landing force and between-limb difference [34]. In another study [10], investigating neuromuscular control on 1140 youth athletes, no age effects, from 9 to 17 years, were noted in limb alignment measured as medial knee displacement during a drop-jump. Although there was an overall performance enhancement in the current study, the median POE scores for the SLS (20 for females, 33 for males) and SLHD (29 for females, 33 for males) were still rather high at follow-up, suggesting that POEs are still present at mid-adolescence. Yet, there were relatively large improvements for FL and DJ for females ( -17 and -16.5 , respectively) and in FL for males $(-17)$ compared to the improvements noted in the SLS and SLHD tests $(0$ to -8$)$. Hence, at mid-adolescence, the use of single-leg tests might be more suitable to detect postural orientation errors. Taken together, improvements in the total POE score between baseline and follow-up were evident for both female and male athletes suggesting some kind of maturity effect.

Table 5 Within-task POE score for the single-leg mini squat (SLS), forward lunge (FL), drop jump (DJ) and single leg hop for distance (SLHD) and total POE score, and differences between baseline and follow-up for female $(n=34)$ and male $(n=52)$ athletes. Values are median and quartiles

\begin{tabular}{|c|c|c|c|c|c|c|}
\hline \multirow[t]{2}{*}{ Task/POE } & \multicolumn{2}{|l|}{ Baseline } & \multicolumn{2}{|l|}{ Follow-up } & \multicolumn{2}{|c|}{ Baseline vs follow-up } \\
\hline & $\begin{array}{l}\text { Females } \\
(n=34)\end{array}$ & $\begin{array}{l}\text { Males } \\
(n=52)\end{array}$ & $\begin{array}{l}\text { Females } \\
(n=34)\end{array}$ & $\begin{array}{l}\text { Males } \\
(n=52)\end{array}$ & $\begin{array}{l}\text { Females } \\
(n=34)\end{array}$ & $\begin{array}{l}\text { Males } \\
(n=52)\end{array}$ \\
\hline SLS & $33(20 ; 40)$ & $33(20 ; 47)$ & $20(13 ; 28.5)$ & $33(20 ; 40)$ & $-7(-0 ; 6.25)^{a}$, & $0(-14 ; 7)^{b}$ \\
\hline FL & $25(17 ; 42)$ & $25(17 ; 33)$ & $8(7 ; 17)$ & $17(8 ; 17)$ & $-17(-33 ; 9)^{\mathrm{a}}$ & $-16(-25 ; 0)^{a}$ \\
\hline DJ & $25(17 ; 425)$ & $17(8 ; 33)$ & $8(0 ; 25)$ & $8(0 ; 23)$ & $-16.5(-25 ; 0)^{a}$ & $-8(-16 ; 0)^{a}$ \\
\hline SLHD & $33(25 ; 50)$ & $42(25-58)$ & $29(17 ; 42)$ & $33(25 ; 42)$ & $-8(-19 ; 8)^{a}$ & $-8(-17 ; 0)^{a}$ \\
\hline Total POE score & $31(24 ; 39.5)$ & $31(25 ; 37)$ & $18(12 ; 25.5)$ & $24(18.5 ; 31)$ & $-10(-18 ;-4)^{a, b}$ & $-7(-1.5 ;-2)^{a, b}$ \\
\hline
\end{tabular}

${ }^{a}$ significant difference between baseline and follow-up $(p \leq 0.007)$

${ }^{\mathrm{b}}$ significant difference between sexes $(p \leq 0.01)$. 
Table 6 Within-task POE score for the SLS, Lunges, DJ and SLHD, and total POE score, given for the different sports type at baseline and follow-up $(n=86)$. Values are median and quartiles

\begin{tabular}{|c|c|c|c|c|c|c|c|c|c|}
\hline \multirow[t]{2}{*}{ Task/POE } & \multicolumn{3}{|l|}{ Baseline } & \multicolumn{3}{|c|}{ Follow-up } & \multicolumn{3}{|c|}{ Baseline vs Follow-up } \\
\hline & $\begin{array}{l}\text { Team } \\
(n=60 ; \text { female } \\
n=21)\end{array}$ & $\begin{array}{l}\text { Individual } \\
(n=20 ; \text { female } \\
n=10)\end{array}$ & $\begin{array}{l}\text { Aesthetic } \\
(n=6 ; \text { female } \\
n=3)\end{array}$ & $\begin{array}{l}\text { Team } \\
(n=60)\end{array}$ & $\begin{array}{l}\text { Individual } \\
(n=20)\end{array}$ & $\begin{array}{l}\text { Aesthetic } \\
(n=6)\end{array}$ & $\begin{array}{l}\text { Team } \\
(n=60)\end{array}$ & $\begin{array}{l}\text { Individual } \\
(n=20)\end{array}$ & $\begin{array}{l}\text { Aesthetic } \\
(n=6)\end{array}$ \\
\hline SLS & $33(20 ; 70)$ & $33(20 ; 42.25)$ & $33(23.5 ; 41.75)$ & $\begin{array}{l}33(20 ; \\
40)\end{array}$ & $\begin{array}{l}23.5(13 \\
38.25)\end{array}$ & $\begin{array}{l}16.5(11.5 ; \\
21.75)^{b}\end{array}$ & $0(-14 ; 7)$ & $\begin{array}{l}-7(-20 ; \\
5.25)^{\mathrm{b}}\end{array}$ & $\begin{array}{l}-20(-21.75 \\
4.5)^{a, b}\end{array}$ \\
\hline Lunges & $25(17 ; 42)$ & $25(10.25 ; 33)$ & $12.5(6 ; 44)$ & $\begin{array}{l}12.5(8 ; \\
17)\end{array}$ & $8(0 ; 17)$ & $12.5(0 ; 37.5)$ & $\begin{array}{l}-17(-25 \\
8)^{b}\end{array}$ & $\begin{array}{l}-16.5 \\
(-31 ; 0)^{b}\end{array}$ & $\begin{array}{l}8,5(-23.25 \\
19)\end{array}$ \\
\hline DJ & $25(10.25 ; 33)$ & $17(8 ; 33)$ & $25(18.75 ; 37.25)$ & $8(0 ; 25)$ & $17(2 ; 31)$ & $8(6 ; 10.25)$ & $\begin{array}{l}-8(-25 \\
0)^{\mathrm{b}}\end{array}$ & $\begin{array}{l}0(-14.25 ; \\
6)\end{array}$ & $\begin{array}{l}-17(-27 \\
12.75)^{\mathrm{b}}\end{array}$ \\
\hline SLHD & $42(27 ; 58)$ & $33(19 ; 56)$ & $25(20.75 ; 39.25)$ & $\begin{array}{l}33(25 ; \\
42)\end{array}$ & $25(17 ; 33)$ & $17(15.75 ; 44)$ & $\begin{array}{l}-8(-17 ; \\
0)^{\mathrm{b}}\end{array}$ & $0(-25 ; 0)^{b}$ & $\begin{array}{l}-8(-12.25 \\
2.5)\end{array}$ \\
\hline $\begin{array}{l}\text { Total POE } \\
\text { score }\end{array}$ & $31(25 ; 39)$ & $25(24 ; 31)$ & $27(18 ; 37)$ & $\begin{array}{l}24(16 ; \\
29)\end{array}$ & $\begin{array}{l}19(14 ; \\
29.5)\end{array}$ & $15(9.5 ; 28)$ & $\begin{array}{l}-8 \\
(-15.5 ;-4)^{b}\end{array}$ & $\begin{array}{l}-6(-16 ;- \\
0.5)^{b}\end{array}$ & $\begin{array}{l}-7(-18.75 ;- \\
1.50)^{\mathrm{b}}\end{array}$ \\
\hline
\end{tabular}

$S L S$ single-leg mini squat, $F L$ forward lunge, $D J$ drop jump, SLHD single leg hop for distance

a significant difference between groups $(p=0.032)$

${ }^{\mathrm{b}}$ significant difference between baseline and follow-up $(p \leq 0.042)$

In the present study, we did not find any sex differences in POEs at the age of 13. Previous have reported that young girls seem to have better postural stability [35] and less body sway than boys [36]. However, these studies included younger non-athlete children, 8-12 and 3-6 years of age, respectively, and measured postural stability (measured as motion of the center of pressure) and not postural orientation.
In the present study, female athletes scored significantly better in total POE score than males at midadolescence. One possible explanation for the sex differences at mid-adolescence could be that females mature earlier than males [37] and thus have reached a more developed motor control system. However, we can only speculate regarding the impact of maturity level as no maturity data were collected.

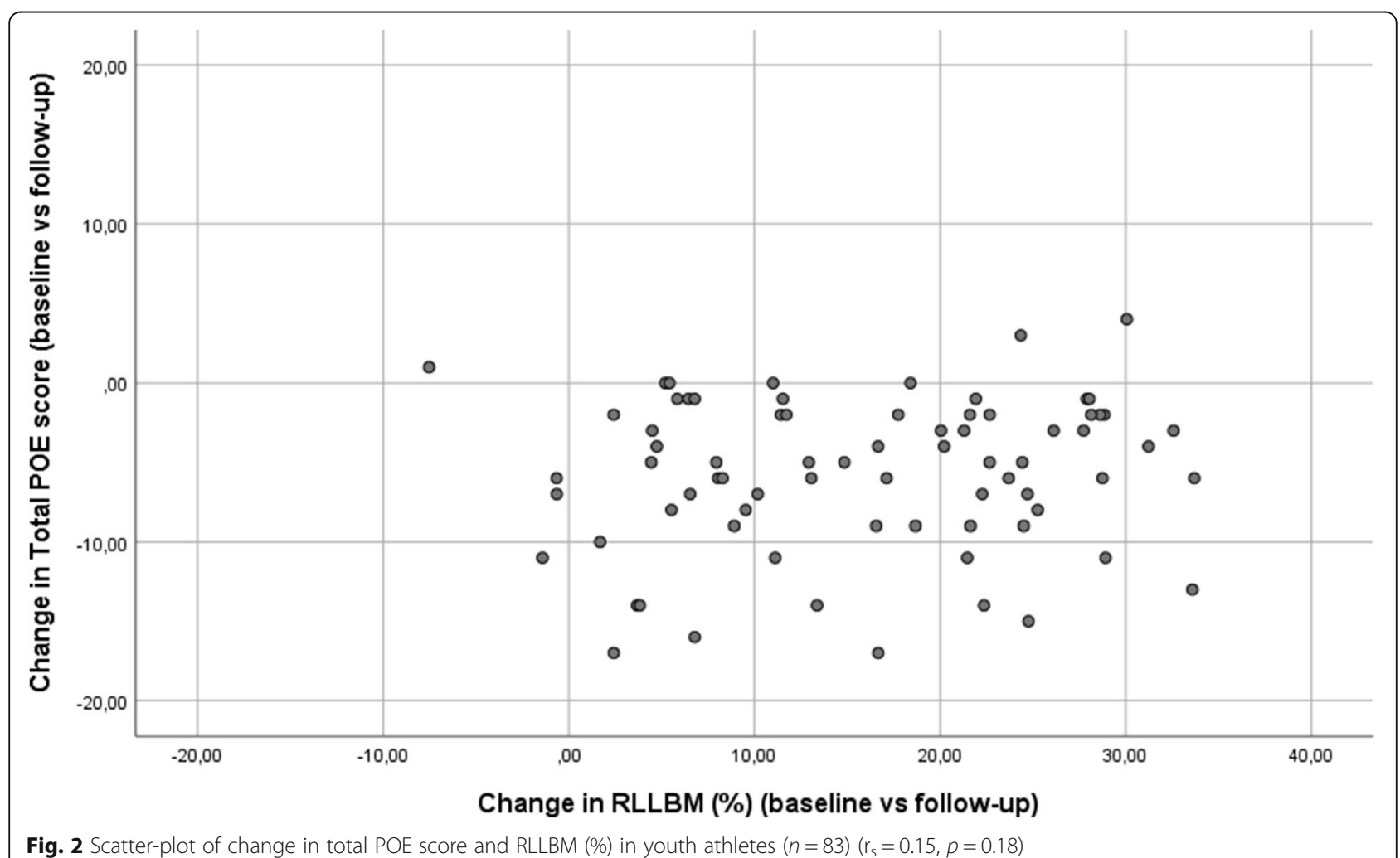

Fig. 2 Scatter-plot of change in total POE score and RLLBM (\%) in youth athletes $(n=83)\left(r_{s}=0.15, p=0.18\right)$ 
No differences in POE scores were found between sports type (team, individual, aesthetic) at baseline whereas aesthetic athletes performed significantly better in SLS at follow-up compared to team athletes. In addition, there were no differences in sex distribution between groups and all sport groups significantly improved in the total POE score. The aesthetic group of athletes included diving, artistic gymnastic and figure skating. It might be that these athletes improve functional performance, including awareness of body alignment, within their sports as it has been demonstrated that sport skill has an impact on balance ability $[38,39]$. Nevertheless, due to the small sample size of aesthetic athletes $(n=6)$ in the present study, further studies are needed on the possible association between sport type and postural orientation.

There was a significant increase of $12 \mathrm{~kg}$ in TBLBM for the male athletes, from baseline to follow-up, corresponding to an increase in rTBLBM of $2 \%$. Although female athletes' TBLBM also increased $(4 \mathrm{~kg})$, the rTBLBM had decreased by $3 \%$ from baseline. The fact that males obtain greater amounts of muscle mass, whereas females gain significantly more fat mass, has previously been reported [40]. In addition, whereas no sex differences in muscle strength seem to exist before the age of 14 , male athletes have a much greater muscle strength development from age 14 to 17 compared to female athletes [10]. However, in our study, no strength data are available, and the development of muscle mass did not seem to influence postural orientation as no relationship was found between the total POE score and RLLBM. Thus, the improvement in POE scores, baseline to follow-up, may be affected by other factors than development of muscle mass, such as neural adaptations to training and natural maturity of the nervous system. Further studies may investigate if muscle strength and state of maturity influence postural orientation.

\section{Strengths and limitations}

This study is the first to provide values of postural orientation and changes over time in youth athletes, related to age, sex and sport type. Another strength is the use of a reliable and valid clinically applicable scoring protocol for assessing POEs. Yet, some limitations in our study need to be recognized. First, the values presented in the present study can only be applied to young athletes aged $13-16$ years and cannot be generalized to the general population of the same age. In addition, only 86 athletes, of the 144 at baseline, were evaluated at the 2-year follow-up. We cannot exclude that the drop-outs could have affected the result, although we observed no clinically relevant differences between follow-up participants and drop-outs in baseline total POE score, or characteristics (weight, height). Another limitation is that no definite maturation evaluation, except from age and TBLBM, or muscle strength assessment was performed. In addition, although injured athletes, at the time of testing, were excluded from participating, we had no data as to whether the included athletes had sustained any previous injuries. Although declared healthy, previous injury might effect physical performance long after onset [41]. Lastly, as there were few aesthetic athletes $(n=6)$ in the present study, a larger sample size is desirable in future investigations to explore any differences in POEs between type of sports.

\section{Conclusion}

Postural orientation errors appear to be quite common in a young athletic population, although improvements were noted from early to mid-adolescence, particularly among females. At early adolescence, there seems to be no sex differences in postural orientation, whereas female athletes may perform better in some functional tests at mid-adolescence. Further, differences between types of sports could not be demonstrated in the present study and the lack of relation between postural orientation and lean body mass indicates that the amount of muscle mass does not seem to influence postural orientation.

\section{Abbreviations}

POEs: Postural Orientation Errors; SLS: Single-leg mini squat; FL: Forward lunge; DJ: Drop jump; SLHD: Single leg hop for distance; FUP: Follow-up; TBLBM: Total body lean body mass; rTBLBM: Relative Total body lean body mass; RLLBM: Right leg lean body mass; Cl: Confidence intervals;

SD: Standard deviations

\section{Acknowledgements \\ Not applicable.}

\section{Authors' contributions}

SRA was responsible for assessing POEs on video, analysis and interpretation of data, and drafting the manuscript. JN contributed to assessing POEs on video, analysis and interpretation of data, and provided feedback on drafts of the manuscript. EA was responsible for data collection, contributed in the analysis and interpretation of data, and provided feedback on drafts of the manuscript. MK contributed with data on lean body mass (LBM),

interpretation of data, and provided feedback on drafts of the manuscript. TP and PW, are responsible for the Malmö Youth Sport Study, and provided feedback on later drafts of the manuscript. All authors read and approved the final manuscript.

\section{Funding}

The Swedish Research Council for Sport Science, Governmental funding of clinical research within the NHS (National Health Services), and the Faculty of Medicine, Lund University. Open Access funding provided by Linnaeus University.

\section{Availability of data and materials}

The data collected and analyzed in the current study are not publicly available due to ethical restrictions, but are available from the corresponding author upon reasonable request. 


\section{Declarations}

\section{Ethics approval and consent to participate}

Ethical approval was received from the Regional Ethical Review Board in Lund, Sweden (2012/745 and 2013/2). All participants achieved written information and both the athlete and their caregivers signed informed consent forms. Also, the study is consistent with World Medical Association Declaration of Helsinki article 23 [42]

\section{Consent for publication}

Not applicable.

\section{Competing interests}

The authors declare that they have no competing interests.

\section{Author details}

'Department of Sport Science, Faculty of Social Sciences, Linnaeus University, SE-391 82 Kalmar, Sweden. ${ }^{2}$ Department of Health Sciences, Lund University, Lund, Sweden. ${ }^{3}$ Clinical and Molecular Osteoporosis Research Unit, Department of Orthopedics and Clinical Sciences, Skåne University Hospital, Lund University, Malmö, Sweden. ${ }^{4}$ Faculty of Education and Society, Department of Sport Sciences, Malmö University, Malmö, Sweden. DDepartment of Translational Medicine, Lund University, Malmö, Sweden. ${ }^{6}$ Department of Medical Imaging and Physiology, Skåne University Hospital, Malmö, Sweden.

Received: 20 April 2021 Accepted: 9 July 2021

Published online: 24 July 2021

\section{References}

1. Wisloff U, Castagna C, Helgerud J, Jones R, Hoff J. Strong correlation of maximal squat strength with sprint performance and vertical jump height in elite soccer players. Br J Sports Med. 2004;38(3):285-8. https://doi.org/1 $0.1136 /$ bjsm.2002.002071

2. Augustsson S. Maximum strength in squats determines jumping height in young female volleyball players. Open Sports Sci J. 2013;6(1):41-6. https:// doi.org/10.2174/1875399X01306010041.

3. Ryman Augustsson S, Arvidsson J, Haglund E. Jump height as performance indicator for the selection of youth football players to national teams. J Sports Med Phys Fitness. 2019;59(10):1669-75. https://doi.org/10.23736/ S0022-4707.19.09739-1.

4. Okada T, Huxel KC, Nesser TW. Relationship between core stability, functional movement, and performance. J Strength Cond Res. 2011;25(1): 252-61. https://doi.org/10.1519/JSC.0b013e3181b22b3e.

5. Sprague PA, Mokha GM, Gatens DR. Changes in functional movement screen scores over a season in collegiate soccer and volleyball athletes. Strength Cond Res. 2014;28(11):3155-63. https://doi.org/10.1519/JSC. 0000000000000506.

6. Ludwig O, Kelm J, Hammes A, Schmitt E, Frohlich M. Neuromuscular performance of balance and posture control in childhood and adolescence. Heliyon. 2020;6(7):e04541. https://doi.org/10.1016/j.heliyon.2020.e04541.

7. Bergeron MF, Mountjoy M, Armstrong N, Chia M, Cote J, Emery CA, et al. International Olympic Committee consensus statement on youth athletic development. Br J Sports Med. 2015;49(13):843-51. https://doi.org/10.1136/ bjsports-2015-094962.

8. Kenney WLWJ, Costill DL. Physiology of sport and exercise. 6th ed. Champaign: Human Kinetics; 2015.

9. Manna I. Growth development and maturity in children and adolescent: relation to sports and physical activity. Am J Sports Sci Med. 2014;2(5A):4850. https://doi.org/10.12691/ajssm-2-5A-11.

10. Barber-Westin SD, Noyes FR, Galloway M. Jump-land characteristics and muscle strength development in young athletes: a gender comparison of 1140 athletes 9 to 17 years of age. Am J Sports Med. 2006;34(3):375-84. https://doi.org/10.1177/0363546505281242.

11. Armstrong N, Welsman JR, Chia MY. Short term power output in relation to growth and maturation. Br J Sports Med. 2001;35(2):118-24. https://doi. org/10.1136/bjsm.35.2.118.

12. Horak FB, Macpherson JM. Postural orientation and equilibrium. In: Rowell LB, Shepherd JT, editors. Handbook of Physiology Exercise: Regulation and Integration of Multiple Systems. 1st ed. New York: American Physiological Society / Oxford Univ. Press; 1996. p. 255-92.
13. Lehmann T, Paschen L, Baumeister J. Single-leg assessment of postural stability after anterior cruciate ligament injury: a systematic review and meta-analysis. Sports Med Open. 2017;3(1):32. https://doi.org/10.1186/s4 0798-017-0100-5.

14. Liang $Y$, Hiley M, Kanosue $K$. The effect of contact sport expertise on postural control. PLoS One. 2019:14((2):e0212334):22-7.

15. Borzucka D, Krecisz K, Rektor Z, Kuczynski M. Differences in static postural control between top level male volleyball players and non-athletes. Sci Rep. 2020;10(1):19334. https://doi.org/10.1038/s41598-020-76390-x.

16. Paillard T, Margnes E, Portet $M$, Breucq A. Postural ability reflects the athletic skill level of surfers. Eur J Appl Physiol. 2011;111(8):1619-23. https://doi.org/1 0.1007/s00421-010-1782-2.

17. Kamath AF, Israelite C, Horneff J, Lotke PA. Editorial: what is varus or valgus knee alignment?: a call for a uniform radiographic classification. Clin Orthop Relat Res. 2010:468(6):1702-4. https://doi.org/10.1007/s11999-010-1334-4.

18. Johnston JT, Mandelbaum BR, Schub D, Rodeo SA, Matava MJ, Silvers Granelli HJ, et al. Video analysis of anterior cruciate ligament tears in professional American football athletes. Am J Sports Med. 2018;46(4):862-8. https://doi.org/10.1177/0363546518756328.

19. Krosshaug T, Nakamae A, Boden BP, Engebretsen L, Smith G, Slauterbeck JR, et al. Mechanisms of anterior cruciate ligament injury in basketball: video analysis of 39 cases. Am J Sports Med. 2007;35(3):359-67. https://doi.org/1 $0.1177 / 0363546506293899$

20. Shimokochi Y, Shultz SJ. Mechanisms of noncontact anterior cruciate ligament injury. J Athl Train. 2008;43(4):396-408. https://doi.org/10.4085/1 062-6050-43.4.396

21. Johnston PT, McClelland JA, Webster KE. Lower limb biomechanics during single-leg landings following anterior cruciate ligament reconstruction: a systematic review and meta-analysis. Sports Med. 2018;48(9):2103-26. https://doi.org/10.1007/s40279-018-0942-0.

22. Noehren B, Abraham A, Curry M, Johnson D, Ireland ML. Evaluation of proximal joint kinematics and muscle strength following $A C L$ reconstruction surgery in female athletes. J Orthop Res. 2014;32(10):1305-10. https://doi. org/10.1002/jor.22678

23. Ortqvist M, Mostrom EB, Roos EM, Lundell $P$, Janarv PM, Werner $S$, et al. Reliability and reference values of two clinical measurements of dynamic and static knee position in healthy children. Knee Surg Sports Traumatol Arthrosc. 2011;19(12):2060-6. https://doi.org/10.1007/s00167-011-1542-9.

24. STROBE Statement 2007 [Available from: http://www.strobe-statement.org/ ?id=available-checklists.

25. Peterson T, Ageberg E, Bremander A, Dencker M, Ek S, Hedenborg S, et al. Malmö Youth Sport Study: A longitudinal study of a secondary school in Malmö, Sweden, specializing in physical activity and sports. https:// idrottsforum.org/: idrottsforum.org 2017.

26. Malmborg JS, Olsson MC, Bergman S, Bremander A. Musculoskeletal pain and its association with maturity and sports performance in 14-year-old sport school students. BMJ Open Sport Exerc Med. 2018:4(1):e000395. https://doi.org/10.1136/bmjsem-2018-000395.

27. Nae J, Creaby MW, Nilsson G, Crossley KM, Ageberg E. Measurement properties of a test battery to assess postural orientation during functional tasks in patients undergoing anterior cruciate ligament injury rehabilitation. J Orthop Sports Phys Ther. 2017;47(11):863-73. https://doi.org/10.2519/ jospt.2017.7270.

28. Nae J, Creaby MW, Ageberg E. Extended version of a test battery for visual assessment of postural orientation errors: face validity, internal consistency, and reliability. Phys Ther. 2020;100(9):1542-56. https://doi.org/10.1093/ptj/ pzaa092.

29. Cohen J. A Coefficient of Agreement for Nominal Scales. Educ Psychol Meas. 1960;20(1):37-46. https://doi.org/10.1177/001316446002000104.

30. Cohen J. Weighted kappa: nominal scale agreement with provision for scaled disagreement or partial credit. Psychol Bull. 1968;70(4):213-20. https://doi.org/10.1037/h0026256.

31. Landis JR, Koch GG. The measurement of observer agreement for categorical data. Biometrics. 1977:33(1):159-74. https://doi.org/10.2307/252 9310

32. Nae J. Is seeing just believing? Measurement properties of visual assessment of postural orientation errors (POEs) in people with anterior cruciate ligament injury [doctoral]. Lund: Lund University; 2020.

33. Madruga-Parera M, Romero-Rodriguez D, Bishop C, Beltran-Valls MR, Latinjak AT, Beato $M$, et al. Effects of Maturation on Lower Limb Neuromuscular Asymmetries in Elite Youth Tennis Players. Sports (Basel). 2019;7(5). 
34. Read PJ, Oliver JL, Myer GD, De Ste Croix MBA, Lloyd RS. The effects of maturation on measures of asymmetry during neuromuscular control tests in elite male youth soccer players. Pediatr Exerc Sci. 2018;30(1):168-75. https://doi.org/10.1123/pes.2017-0081.

35. Smith AW, Ulmer FF, Wong del P. Gender differences in postural stability among children. J Hum Kinet. 2012;33(2012):25-32. https://doi.org/10.2478/ v10078-012-0041-5.

36. Demura S, Kitabayashi T, Uchiyama M. Body sway characteristics during static upright posture in young children. Sport Sci Health. 2006;1 (4):158-61. https://doi.org/10.1007/s11332-006-0028-5.

37. Malina RM. Top 10 research questions related to growth and maturation of relevance to physical activity, performance, and fitness. Res Q Exerc Sport. 2014;85(2):157-73. https://doi.org/10.1080/02701367.2014.897592.

38. Vuillerme N, Nougier $\mathrm{V}$. Attentional demand for regulating postural sway: the effect of expertise in gymnastics. Brain Res Bull. 2004;63(2):161-5. https://doi.org/10.1016/j.brainresbull.2004.02.006.

39. Gautier G, Thouvareca R, Larue J. Influence of experience on postural control: effect of expertise in gymnastics. J Mot Behav. 2008;40(5):400-8. https://doi.org/10.3200/JMBR.40.5.400-408.

40. Loomba-Albrecht LA, Styne DM. Effect of puberty on body composition. Curr Opin Endocrinol Diabetes Obes. 2009;16(1):10-5. https://doi.org/10.1 097/MED.0b013e328320d54c.

41. Tengman E, Brax Olofsson L, Nilsson KG, Tegner Y, Lundgren L, Hager CK. Anterior cruciate ligament injury after more than 20 years: I. physical activity level and knee function. Scand J Med Sci Sports. 2014;24(6):e491-500. https://doi.org/10.1111/sms.12212

42. World Medical A. World medical association declaration of Helsinki: ethical principles for medical research involving human subjects. JAMA. 2013; 310(20):2191-4.

\section{Publisher's Note}

Springer Nature remains neutral with regard to jurisdictional claims in published maps and institutional affiliations.

Ready to submit your research? Choose BMC and benefit from:

- fast, convenient online submission

- thorough peer review by experienced researchers in your field

- rapid publication on acceptance

- support for research data, including large and complex data types

- gold Open Access which fosters wider collaboration and increased citations

- maximum visibility for your research: over $100 \mathrm{M}$ website views per year

At $\mathrm{BMC}$, research is always in progress.

Learn more biomedcentral.com/submissions 